\title{
Evaluation of Green Growth Capacity in National New Areas
}

\author{
Dongfang Zhao ${ }^{*}$, Hua Shang1, Yuli Wang2, Chunyou Wu ${ }^{1}$ \\ ${ }^{1}$ Faculty of Management and Economics, Dalian University of Technology, Dalian, China \\ ${ }^{2}$ Economic Development and Statistics Bureau, Dalian Free Trade Zone Administration, Dalian, China \\ Email: ${ }^{* 736935540 @ q q . c o m ~}$
}

How to cite this paper: Zhao, D. F., Shang, H., Wang, Y. L., \& Wu, C. Y. (2018). Evaluation of Green Growth Capacity in National New Areas. Chinese Studies, 7, 197209.

https://doi.org/10.4236/chnstd.2018.73017

Received: May 9, 2018

Accepted: June 19, 2018

Published: June 22, 2018

Copyright (c) 2018 by authors and Scientific Research Publishing Inc. This work is licensed under the Creative Commons Attribution International License (CC BY 4.0).

http://creativecommons.org/licenses/by/4.0/

\begin{abstract}
As a special policy area under China's new normal economic background, the National New District plays a key role in the realization of economic and social development and green growth. This paper constructs an evaluation index system for green growth capacity from five aspects: government support capabilities, corporate green capabilities, NGO supervision and guidance, public participation capabilities, and park output benefits. Various methods are used to measure green growth capacities of these four National New Districts including the Jinpu, Pudong, Binhai, and Nansha. The results show that government support capability has the greatest impact on the green growth capacity of the state-level new district and Pudong has the largest green growth capacity, followed by Binhai, Nansha and Jinpu.
\end{abstract}

\section{Keywords}

Green Growth Capacity, National New Area, China, Evaluation

\section{Introduction}

At present, China economic development is in the "structural" deceleration which is called "new normal". This is a state of development that pays more attention to the "quality" rather than "quantity" of economic growth. The main characteristics are that "from high speed growth to medium and high speed growth, from factor driven, investment driven to innovation driven". Most scholars believe that the new momentum of economic growth under the new normal should take the development of industry as the first step. The construction of the national new area which emphasize on the green development of industry and the innovation of technology green is the key to the optimization and upgrading of the economic structure and the transformation of the mode of 
economic growth under the new normal state. At the same time, the central economic work conference held at the end of 2017 made it clear that the prevention and control of pollution is one of the three major battles in the next three years. It shows the determination of Chinese government to chase the green growth path. As a special policy area, the state-level new area is related not only to the economic and social development of a certain region, but also to the overall strategic layout of the economic and social development and the reconstruction of the regional spatial pattern. It is a forceful practice of the call for "upgrading the industrial innovation with the supply side reform" and "pollution prevention and control".

After more than 20 years of exploration and development, China has set up 19 new national new areas and made certain achievements. However, there are still many problems, such as unclear management authority, lack of industrial chain in the new area, lack of innovation interaction with scientific research institutions, and low level of regional recycling and low carbon management (Zhao et al., 2018; Li, 2015). At the same time, in recent years, green growth as a new growth mode which emphasizes the pursuit of economic growth and development, and to prevent the deterioration of the environment, loss of biodiversity and natural resources sustainable utilization has been widely recognized by the international community. Therefore, academia and industry generally believe that in the context of China's actively promoting the transformation of economic growth mode and realizing the green growth of economy, the cultivation of green growth capacity will become the key engine to solve the development dilemma of state-level new district.

At present, with the importance of the national economic development in the national economic development, some scholars have done a certain research on the national new area. But it mainly focuses on location selection (Peng et al., 2015), function orientation evaluation (Ye et al., 2015), management system and power allocation ( $\mathrm{Li}, 2015)$, new area water resources management (Li et al., 2015) and so on, rarely involving green growth and its capability. For green growth research, at present, more remain in the connotation of green growth, path of formation, influence and other aspects. Few scholars start from the perspective of ability to launch a thematic study of green growth capacity. It can be seen that the national new area research and green growth capacity has not yet formed effective integration. The research on the green growth ability of the national new area is relatively scarce. Few scholars have carried out quantitative evaluation research on the green growth ability of the national new area. Therefore, this research uses the "green development index", "low carbon green index", "green economic development index", "green" and other related research results, considering the unique of national district, and based on the stakeholder theory. Constructing the evaluation index system of green growth ability of national district from the government, NGO, enterprise and the public level. On this basis, this paper uses the combination weighting method including G1 method, G2 method, entropy method and deviation maximization 
method to make an empirical analysis of the green growth capacity of 19 national new areas.

This study is organized as follows. Section 2 establishes the evaluation index system for green growth capacity of National New Areas. Section 3 proposes the evaluation model for green growth capacity, and an empirical analysis is conducted in Section 4. Finally, Section 5 presents the concluding remarks, limitations of the study, and directions for future research.

\section{Evaluation Index System for Green Growth Capacity of National New Areas}

Selecting scientific and reasonable evaluation index is the key to construct the evaluation index system of green growth capacity of the national new area. Therefore, this article follows the following principles in the process of index selection, 1) Scientific principle. The index system must be built on the basis of science and based on the actual situation of our country, which can objectively reflect the concrete situation of the green growth of the national level new area. 2) Logic principle. Evaluation indicators need concise, clear and logical language, so as to facilitate the evaluation of experts in evaluating reception and application, maintaining consistency and avoiding ambiguity. 3) Maneuverability principle. The index system needs data obtained from the current national new area administrative committee, and the economic meaning of the selected indicators should be clear, and the representative main indicators and comprehensive indicators should be selected as far as possible. 4) Advancement principle. The selected indexes can reflect the latest development of green growth ability in time, and there is no lag. Freeman (1984) believes that the success of an organization or enterprise depends on how to manage the relationship between key stakeholders [6]. Therefore, the leaders of the organization or enterprise should focus on the needs and well-being of the stakeholders (Ditlev-Simonsen \& Wenstøp, 2013), that is, stakeholder theory. At present, stakeholder theory has been widely applied in different fields, such as green supply chain management, eco industrial park sustainable development and corporate social responsibility evaluation. Similarly, the construction of green growth capacity of state-level new area as a complex system engineering will also be influenced by many factors such as government, enterprises, NGO, and the public. Therefore, based on the above principles, this article is based on the stakeholder theory and from the four stakeholders, such as the government, the enterprise, the NGO and the public.

The evaluation index system of green growth ability in the national district includes 4 aspects of government support capability, enterprise ability, NGO green supervision, public participation ability, and 17 secondary indicators, and 44 tertiary indicators (See Table 1).

\section{Evaluation Model for Green Growth Capacity of National New Areas}

The evaluation model is as follows. 
Table 1. Evaluation index system of green growth capacity in National New Area.

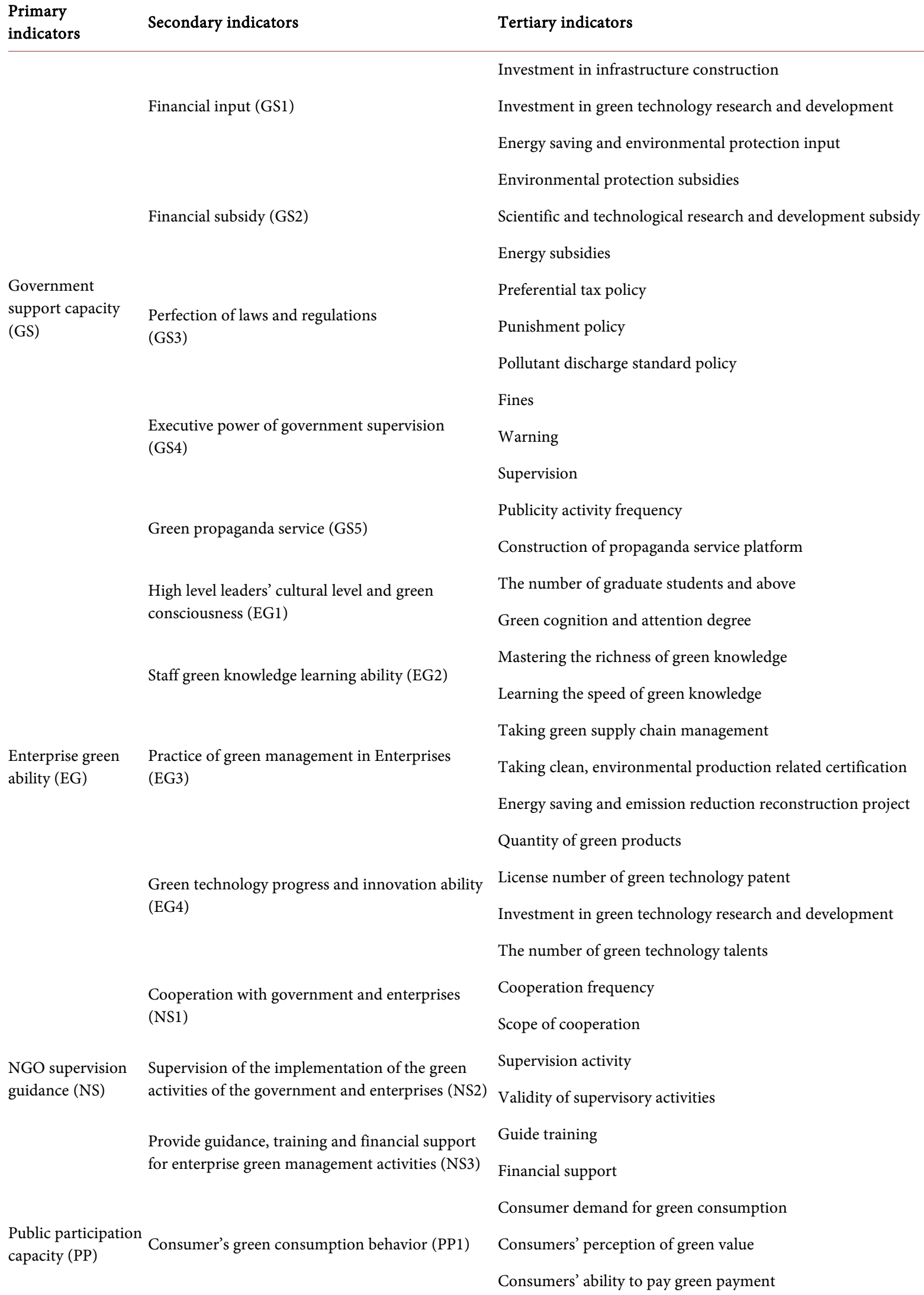

\section{indicators}

Financial input (GS1)

Financial subsidy (GS2)

\section{Government}

support capacity

(GS)

Perfection of laws and regulations

(GS3)

Executive power of government supervision (GS4)

Green propaganda service (GS5)

High level leaders' cultural level and green consciousness (EG1)

Staff green knowledge learning ability (EG2)

Enterprise green ability (EG)

Practice of green management in Enterprises (EG3)

Green technology progress and innovation ability (EG4)

Cooperation with government and enterprises (NS1)

NGO supervision guidance (NS)

Supervision of the implementation of the green activities of the government and enterprises (NS2)

Provide guidance, training and financial support for enterprise green management activities (NS3)

Public participation capacity (PP)

Consumer's green consumption behavior (PP1)

Investment in infrastructure construction

Investment in green technology research and development

Energy saving and environmental protection input

Environmental protection subsidies

Scientific and technological research and development subsidy

Energy subsidies

Preferential tax policy

Punishment policy

Pollutant discharge standard policy

Fines

Warning

Supervision

Publicity activity frequency

Construction of propaganda service platform

The number of graduate students and above

Green cognition and attention degree

Mastering the richness of green knowledge

Learning the speed of green knowledge

Taking green supply chain management

Taking clean, environmental production related certification

Energy saving and emission reduction reconstruction project

Quantity of green products

License number of green technology patent

Investment in green technology research and development

The number of green technology talents

Cooperation frequency

Scope of cooperation

Supervision activity

Validity of supervisory activities

Guide training

Financial support

Consumer demand for green consumption

Consumers' perception of green value

Consumers' ability to pay green payment 
Participation of local residents in green construction in New Area (PP2)

Economic performance (PO1)

Park output benefit(PO)

Environmental benefit (PO2)

Social benefit (PO3)
Attention and supervision of green construction in New Area

The frequency of participating in the environmental protection public welfare activities in the New Area

Total business income of new area enterprises accounts for the proportion of GDP in the region

The total amount of tax revenue in the new area accounts for the proportion of the total tax revenue in the region

Market share of green products in New Area

"Near zero" emission of pollutants

Recycling and reuse of waste

Unit GDP energy consumption

Employment accounts for the proportion of local workers

Per capita wage level in the New Area

Source: From the literature review.

The data collection and processing of this study are shown in Figure 1. Firstly, based on the raw data from collection, the data should be standardized to eliminate the effect of index dimension and quantity of data. Secondly, this paper uses G1, G2, entropy method and discrepancy maximization method to calculate index weights. Thirdly, based on the objective function and the principle of maximum entropy, the combined weights will be calculated. Finally, the value of green growth capability for each research object will be calculated.

The data using in this study was obtained through questionnaire. There are two methods for the survey. The first method is with the aid of the personal relationship to investigate, such as telephone interviews, field surveys, and fill out questionnaires on the spot. And this method is applied in the Jinpu New District and Binhai New District.

The second method is to obtain the contact information with the help of the local government authorities, and send electronic questionnaires via email. This method is mainly used in the Pudong New District and Nansha New District.

\subsection{Normalization of Raw Data}

Setting $x_{i j}$ to represent the normalized value, and $v_{i j}$ represents the value of $i$ object and the $j$ target, and $n$ represents the number of evaluation objects. As the index of this paper is positive, it is normalized according to the forward scoring formula (Li et al., 2004):

$$
x_{i j}=\frac{v_{i j}-\min _{1 \leq i \leq n}\left(v_{i j}\right)}{\max _{1 \leq i \leq n}\left(v_{i j}\right)-\min _{1 \leq i \leq n}\left(v_{i j}\right)}
$$

\subsection{Single Evaluation Method of Empowerment}

1) Calculation of weight by G1 method [9] 


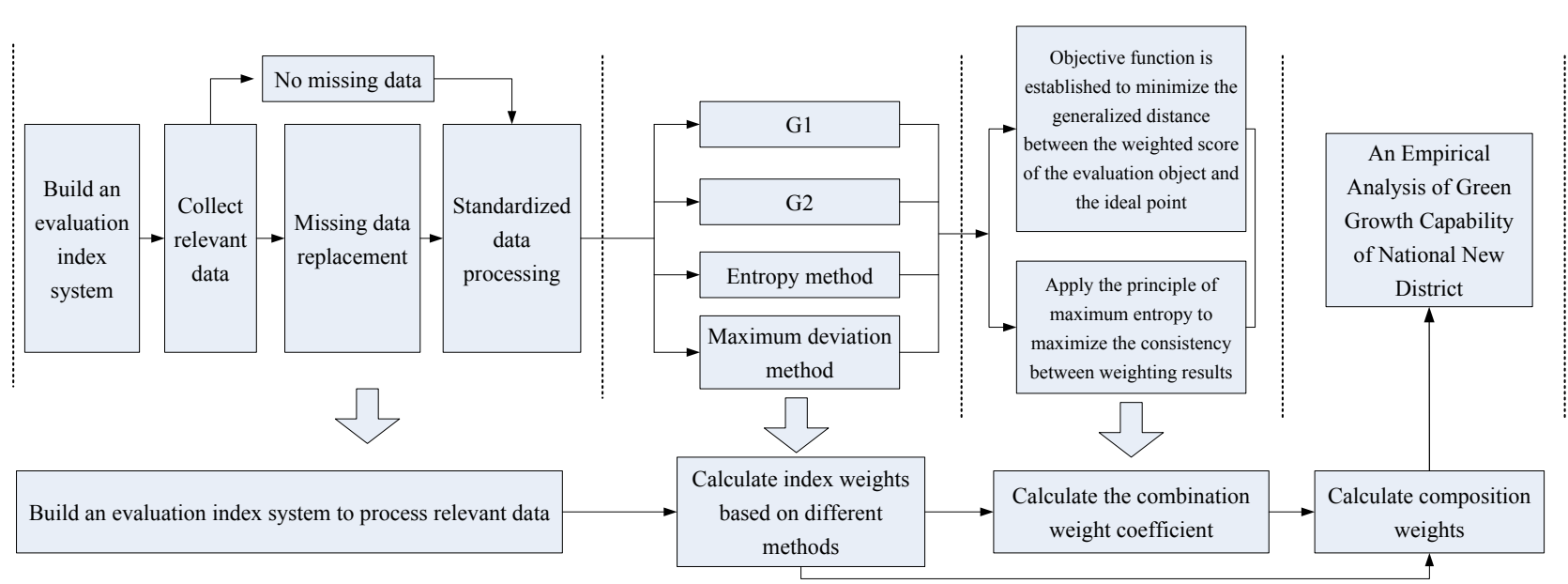

Figure 1. Evaluation model based on combination weighting method. Source: From the literature review.

The G1 method is a subjective evaluation method, which mainly reflects the importance of the index by the subjective sort of the experts.

a) Determining the order relationship of evaluation indicators, that is, the subjective judgment of the importance of each index,

b) Subjectively valuing the importance $R_{i}$ of adjacent indexes $x_{i}$ and $x_{i-1}$,

c) Using formula (2), Calculating the weight of the $k$ index.

$$
w_{k}=1 /\left(1+\sum_{i=2}^{k} \Pi R_{i}\right)
$$

d) The weight of the weight $w_{k}$ can be obtained by the weight of the $k-$ $1, \ldots, 2,3$ index, as shown in formula (3). Among them, $w_{i-1}$ represents the weight of the $i-1$ index, and $R_{i}$ represents the subjective assignment given by the expert.

$$
w_{i-1}=R_{i} * w_{i}
$$

2) Calculation of weight by G2 method (Wang et al., 2005)

The G2 method is also a subjective evaluation method, but unlike the G1 method, experts need to identify the most unimportant indicators.

a) Determining the order relationship of evaluation indicators, that is, the subjective judgment of the importance of each index,

b) The experts identify the least important indicator $x_{k}$,

c) The experts determine the importance of $x_{i}$ and $x_{k}$ and give a subjective assignment,

d) Using formula (4) to calculate the weight of the $i$ indicator. Among them, $w_{i}$ represents the weight of the $i$, and $D_{i}$ represents the subjective assignment given by experts.

$$
w_{i}=D_{i} / \sum_{i=1}^{k} D_{i}
$$

3) Determination of weight by entropy method (Guo, 2002)

Entropy method reflects the importance of the index by calculating the dif- 
ference between the values of the same index. The greater the numerical difference, the more important the index is.

a) Using formula (5), and calculating the weight of $r_{i j} . x_{i j}$ is the original value of the object $i$ and the indicator $j, i=1,2, \cdots, n ; j=1,2, \cdots, m$;

$$
r_{i j}=x_{i j} / \sum_{i=1}^{n} x_{i j}
$$

b) Using formula (6), and calculating the information entropy $e_{j}$ of the indicator $j$, and $k=1 / \ln n, n$ is the number of indicators;

$$
e_{j}=-k \sum_{i=1}^{n} r_{i j} \ln \left(r_{i j}\right)
$$

c) Computing the redundancy of information entropy.

$$
d_{j}=1-e_{j}
$$

d) Setting $w_{j}$ as the weight of the index $j$, and the calculation formula is as follows,

$$
w_{j}=d_{j} / \sum_{j=1}^{m} d_{j}
$$

4) Calculation weight of deviation maximization method (Huang et al., 2012)

The maximum deviation method is to calculate the importance of the index by calculating the proportion of the total deviation of the total index $j$, and the greater the proportion, the more important the index is.

a) Setting $s_{i j}$ as the value of the object $i$ and the indicator $j$ through the normalization. Setting $w_{j}$ as the weight of indicator $j$. For $j$, using $H_{i j}(w)$ to show the deviation of $i$ and other indexes $(k=1,2, \cdots, n)$,

$$
H_{i j}(w)=\sum_{j=1}^{m}\left|s_{i j} w_{j}-s_{i k} w_{j}\right|
$$

b) Calculating $j$, the total deviation of all objects from other objects,

$$
H_{j}(w)=\sum_{i=1}^{n} \sum_{k=1}^{n}\left|s_{i j}-s_{i k}\right| w_{j}
$$

c) According to the principle of maximum deviation, the optimizing model is

$$
\begin{aligned}
& \max H(w)=\sum_{j=1}^{m} \sum_{i=1}^{n} \sum_{k=1}^{n}\left|s_{i j}-s_{i k}\right| w_{j} \\
& \text { s.t. }\left\{\begin{array}{l}
w_{j} \geq 0 \\
\sum_{j=1}^{m} w_{j}^{2}=1
\end{array}\right.
\end{aligned}
$$

d) The above model is calculated and normalized, and the weight of the deviation method is obtained.

$$
w_{j}=\frac{\sum_{i=1}^{n} \sum_{k=1}^{n}\left|s_{i j}-s_{i k}\right|}{\sum_{j=1}^{m} \sum_{i=1}^{n} \sum_{k=1}^{n}\left|s_{i j}-s_{i k}\right|}
$$




\subsection{Calculation of Combination Weight Coefficient}

This paper calculates the combination weight coefficient $a_{c}$ based on the following two factors, $\sum_{c=1}^{s} a_{c}=1 \quad(s=1,2,3,4)$.

a) To ensure that the weighted scores of each evaluation object and the generalized distance of the ideal point are minimization. $l_{i}$ is the generalized distance between the weighted scores and the ideal points of each evaluation object. $w_{j c}$ is the weight of the $j$ index of the $c$ method of empowerment. $x_{i j}$ is a normalized value for the $j$ index of $i$ object.

$$
\min \sum_{i=1}^{n} l_{i}=\sum_{i=1}^{n} \sum_{j=1}^{m} \sum_{c=1}^{s} a_{c} w_{j}^{c}\left(1-x_{i j}\right)
$$

b) The principle of Jaynes maximum entropy is introduced to reflect the degree of consistency among various empowerment results. Based on the principle of minimum difference of weighting results, the objective function is constructed as formula (14). $\theta(0 \leq \theta \leq 1)$ is the equilibrium coefficient between two targets, according to the research of Li Baizhou (Li et al., 2013), $\theta=0.5$.

$$
\begin{aligned}
& \min \theta \sum_{i=1}^{n} \sum_{j=1}^{m} \sum_{c=1}^{s} a_{c} w_{j}^{c}\left(1-x_{i j}\right)+(1-\theta) \sum_{c=1}^{s} a_{c} \ln a_{c} \\
& \text { s.t. } \sum_{c=1}^{s} a_{c}=1, x_{c} \geq 0
\end{aligned}
$$

c) Constructing the combination coefficient of Lagrange's function.

$$
a_{c}=\frac{\exp \left\{-\left[1+\theta \sum_{i=1}^{n} \sum_{j=1}^{m} w_{j}^{c}\left(1-x_{i j}\right) /(1-\theta)\right]\right\}}{\sum_{c=1}^{s} \exp \left\{-\left[1+\theta \sum_{i=1}^{n} \sum_{j=1}^{m} w_{j}^{c}\left(1-x_{i j}\right) /(1-\theta)\right]\right\}}
$$

\subsection{Calculating the Combinatorial Weight}

Calculating the weights of each index by G1 method, G2 method, entropy method and maximum deviation method, $w_{c}(c=1,2,3,4)$, and using formula (16) to calculate the combination weight.

$$
w=\sum_{c=1}^{s} a_{c} w_{c}
$$

Multiplying the transfer a of the combination weight $w^{T}$ obtained by formula (16) and the result of standardization of each index to get the evaluation score of green growth ability of each national level new area $S$.

$Q_{i}(i=1,2,3, \cdots, n)$ is the evaluation score of each area.

$$
S=W^{\mathrm{T}} \times X=\left(Q_{1}, Q_{2}, Q_{3}, \cdots, Q_{n}\right)
$$

\section{Empirical Analysis}

This article takes Jinpu New District, Pudong New District, Binhai New District and Nansha New District as the research objects with 2017 as the research time. 
The raw data of related indicators were obtained through field visits and research.

The reasons for taking Jinpu New District, Pudong New District, Binhai New District and Nansha New District as the research objects are as follows.

Firstly, these areas are located in coastal cities. The coastal cities are representative, which occupies important positions in the development strategy of national new districts.

Secondly, these four areas have been built before 2015, and their development scale and level were more mature. So the research results are basically stable.

Finally, as the authors maintain close contact with the managers of these four new districts, it can ensure data availability, timely and reliability.

This paper takes the evaluation of green growth capacity as the main line, and focuses on these four new areas' development levels of green growth capacity. Therefore, the internal mechanism of green growth capacity is not the key of this study. In the future research, we will conduct in-depth research on the internal mechanism of green growth capacity.

After obtaining the original data of the relevant indicators, this paper carries out a standardized process for each index to find the formula (1)

$x_{i j}(i=1,2,3,4 ; j=1,2, \cdots, 44)$. The specific calculation process and results are as follows.

\subsection{The G1 Method Calculates Weights}

1) According to expert opinion, the relative importance of government support capability (GS), corporate green capacity (EG), NGO supervision and guidance (NS), public participation capacity (PP), and the output efficiency of the park $(\mathrm{PO})$ is ranked. $\mathrm{PO}>\mathrm{GS}>\mathrm{PP}>\mathrm{NS}$.

2) Compare the importance of neighboring children's abilities and assign them. Like $R_{5}=\mathrm{EG} / \mathrm{PO}=1.2, R_{4}=\mathrm{PO} / \mathrm{GS}=1.4, R_{3}=\mathrm{GS} / \mathrm{PP}=1.1, R_{2}=\mathrm{PP} / \mathrm{NS}=1.2$.

3) Bring the equivalent value into the formula (2) (3) to obtain the government support ability (GS), the corporate green capacity (EG), the NGO supervision and guidance (NS), the public participation capacity (PP), and the park output efficiency (PO) The weight of G1 method. Similarly, through the ratio of the importance of the adjacent indicators of indicator layer, the weight of indicator G1 method can also be obtained, as shown in Table 2.

\subsection{The G2 Method Calculates Weights}

1) Determine the most insignificant sub-capacity factor U5 by an expert.

2) According to expert opinion, the ratio of the importance of the remaining factors to T3 is assigned, like $D_{1}=\mathrm{U} 1 / \mathrm{U} 5=1.7, D_{2}=\mathrm{U} 2 / \mathrm{U} 5=1.5, D_{3}=\mathrm{U} 3 / \mathrm{U} 5=$ 1.4, $D_{4}=\mathrm{U} 4 / \mathrm{U} 5=1.3, D_{5}=\mathrm{U} 5 / \mathrm{U} 5=1$.

3) Bring Di into Equation (4) to get the G2 weights of the five. Similarly, the ratio of the importance of the adjacent indicators at the indicator level can also be obtained by using the G2 method weights at the indicator level, as shown in Table 2. 
Table 2. Evaluation Index Weights.

\begin{tabular}{|c|c|c|c|c|c|c|c|c|c|}
\hline Index & G1 & G2 & $\begin{array}{l}\text { Entropy } \\
\text { method }\end{array}$ & $\begin{array}{c}\text { Maximum } \\
\text { deviation }\end{array}$ & Index & G1 & G2 & $\begin{array}{l}\text { Entropy } \\
\text { method }\end{array}$ & $\begin{array}{c}\text { Maximum } \\
\text { deviation }\end{array}$ \\
\hline GS11 & 0.0163 & 0.0131 & 0.0180 & 0.0216 & EG42 & 0.0203 & 0.0161 & 0.0322 & 0.0226 \\
\hline GS12 & 0.0198 & 0.0184 & 0.0334 & 0.0222 & EG43 & 0.0290 & 0.0190 & 0.0206 & 0.0240 \\
\hline GS13 & 0.0180 & 0.0170 & 0.0227 & 0.0231 & EG44 & 0.0223 & 0.0205 & 0.0187 & 0.0229 \\
\hline GS21 & 0.0128 & 0.0138 & 0.0212 & 0.0220 & NS11 & 0.0209 & 0.0273 & 0.0228 & 0.0239 \\
\hline GS22 & 0.0128 & 0.0165 & 0.0226 & 0.0216 & NS12 & 0.0209 & 0.0248 & 0.0171 & 0.0219 \\
\hline GS23 & 0.0116 & 0.0152 & 0.0394 & 0.0251 & NS21 & 0.0230 & 0.0382 & 0.0207 & 0.0228 \\
\hline GS31 & 0.0121 & 0.0118 & 0.0206 & 0.0233 & NS22 & 0.0230 & 0.0347 & 0.0238 & 0.0222 \\
\hline GS32 & 0.0157 & 0.0107 & 0.0207 & 0.0228 & NS31 & 0.0190 & 0.0327 & 0.0269 & 0.0219 \\
\hline GS33 & 0.0173 & 0.0139 & 0.0415 & 0.0239 & NS32 & 0.0190 & 0.0298 & 0.0207 & 0.0228 \\
\hline GS41 & 0.0136 & 0.0146 & 0.0200 & 0.0210 & PP11 & 0.0251 & 0.0328 & 0.0171 & 0.0219 \\
\hline GS42 & 0.0124 & 0.0133 & 0.0273 & 0.0232 & PP12 & 0.0276 & 0.0205 & 0.0207 & 0.0228 \\
\hline GS43 & 0.0150 & 0.0146 & 0.0254 & 0.0223 & PP13 & 0.0228 & 0.0287 & 0.0207 & 0.0228 \\
\hline GS51 & 0.0169 & 0.0132 & 0.0203 & 0.0232 & PP21 & 0.0378 & 0.0390 & 0.0180 & 0.0222 \\
\hline GS52 & 0.0169 & 0.0171 & 0.0200 & 0.0213 & PP22 & 0.0378 & 0.0355 & 0.0269 & 0.0219 \\
\hline EG11 & 0.0254 & 0.0233 & 0.0163 & 0.0220 & PO11 & 0.0249 & 0.0310 & 0.0245 & 0.0234 \\
\hline EG12 & 0.0330 & 0.0180 & 0.0180 & 0.0222 & PO12 & 0.0273 & 0.0284 & 0.0284 & 0.0241 \\
\hline EG21 & 0.0244 & 0.0216 & 0.0164 & 0.0205 & PO13 & 0.0226 & 0.0258 & 0.0270 & 0.0228 \\
\hline EG22 & 0.0244 & 0.0238 & 0.0180 & 0.0222 & $\mathrm{PO} 21$ & 0.0373 & 0.0284 & 0.0171 & 0.0219 \\
\hline EG31 & 0.0354 & 0.0206 & 0.0217 & 0.0233 & $\mathrm{PO} 22$ & 0.0286 & 0.0260 & 0.0238 & 0.0222 \\
\hline EG32 & 0.0211 & 0.0159 & 0.0215 & 0.0230 & $\mathrm{PO} 23$ & 0.0239 & 0.0237 & 0.0232 & 0.0252 \\
\hline EG33 & 0.0253 & 0.0254 & 0.0187 & 0.0221 & PO31 & 0.0340 & 0.0338 & 0.0243 & 0.0247 \\
\hline EG41 & 0.0184 & 0.0146 & 0.0223 & 0.0247 & PO32 & 0.0340 & 0.0372 & 0.0184 & 0.0223 \\
\hline
\end{tabular}

Source: From the calculation.

\subsection{Calculate Composition Weights}

The weights of each single evaluation method in Table 2 are brought into Equation (15) to obtain the combined weight coefficient $a_{c}=(0.2583,0.2542,0.2370,0.2503)$. This combination weight coefficient is brought into Equation (16), and the combined weight of each index can be obtained, as shown in Table 3. Table 3 shows that the government support capability (GS), corporate green capacity (EG), NGO supervision and guidance (NS), public participation capacity (PP), and the park output efficiency (PO) mean $0.2693,0.2435$, and 0.1454 respectively. 0.1313 , 0.2107 . It can be seen that at present, government support capabilities have the greatest impact on the green growth capacity of the state-level new districts, followed by corporate green capabilities, park output benefits, NGO supervision, and public participation. 
Table 3. Evaluation Index Combination Weights.

\begin{tabular}{cccccccc}
\hline Index & $\begin{array}{c}\text { Combination } \\
\text { weight }\end{array}$ & Index & $\begin{array}{c}\text { Combination } \\
\text { weight }\end{array}$ & Index & $\begin{array}{c}\text { Combination } \\
\text { weight }\end{array}$ & Index & $\begin{array}{c}\text { Combination } \\
\text { weight }\end{array}$ \\
\hline GS11 & 0.0172 & GS43 & 0.0192 & EG42 & 0.0226 & PP13 & 0.0238 \\
GS12 & 0.0232 & GS51 & 0.0184 & EG43 & 0.0232 & PP21 & 0.0295 \\
GS13 & 0.0201 & GS52 & 0.0188 & EG44 & 0.0211 & PP22 & 0.0306 \\
GS21 & 0.0174 & EG11 & 0.0219 & NS11 & 0.0237 & PO11 & 0.0260 \\
GS22 & 0.0183 & EG12 & 0.0229 & NS12 & 0.0212 & PO12 & 0.0271 \\
GS23 & 0.0225 & EG21 & 0.0208 & NS21 & 0.0263 & PO13 & 0.0245 \\
GS31 & 0.0168 & EG22 & 0.0222 & NS22 & 0.0260 & PO21 & 0.0264 \\
GS32 & 0.0174 & EG31 & 0.0254 & NS31 & 0.0251 & PO22 & 0.0252 \\
GS33 & 0.0238 & EG32 & 0.0204 & NS32 & 0.0231 & PO23 & 0.0240 \\
GS41 & 0.0172 & EG33 & 0.0230 & PP11 & 0.0243 & PO31 & 0.0293 \\
GS42 & 0.0188 & EG41 & 0.0200 & PP12 & 0.0230 & PO32 & 0.0282 \\
\hline
\end{tabular}

Source: From the calculation.

\subsection{Comprehensive Evaluation Analysis}

From the point of view of total scores, the standardized data of each indicator and the combination weight coefficient are brought into formula (17), and the total score of the evaluation object can be obtained as shown in Table 4. Among them, Jinpu New District 0.2685, Pudong New District 0.8253, Binhai New District 0.5680, Nansha New District 0.3226 It can be seen that Pudong New Area's green growth capacity is far from the other three new districts. Jinpu New District, as a newly built new district, has a lower level of green growth than the other three new districts. The main reason for this result is that Jinpu New District is significantly weaker than the other three new districts in terms of government support, NGO supervision and guidance, and public participation. It still needs to be strengthened and improved.

\section{Conclusion}

In this paper, through the effective review of related literature, combined with the development status of China's national-level new districts, we construct the evaluation index system for green growth capacity of the national new district from the five aspects of government support capacity, corporate green capacity, NGO supervision and guidance, public participation capacity, and park output efficiency to empirically measure the green growth capacity of Jinpu New District, Pudong New Area, Binhai New Area and Nansha New District. Compared with similar papers, the innovations in this paper are as follows: 1) Based on the perspective of the value chain, an evaluation index of the green growth capacity of the national-level new district was constructed; 2) In the evaluation method, this paper adopts not a single evaluation method, but adopts The G1 method, G2 
Table 4. Evaluation scores of each new district.

\begin{tabular}{ccccccc}
\hline & Total Score & GS & EG & NS & PP & PO \\
\hline Jinpu & 0.2685 & 0.0352 & 0.0929 & 0.0421 & 0.0470 & 0.0512 \\
Pudong & 0.8253 & 0.1857 & 0.2288 & 0.1024 & 0.1159 & 0.1925 \\
Binhai & 0.5680 & 0.1533 & 0.1657 & 0.0806 & 0.0806 & 0.1243 \\
Nansha & 0.3226 & 0.1153 & 0.0402 & 0.0577 & 0.0603 & 0.0490 \\
\hline
\end{tabular}

Source: From the calculation.

method, entropy method, and the optimal combination weighting method of the maximum deviation method are combined to effectively avoid the subjective and objective evaluation of their own deficiencies.

The final study found that government support capacity has the greatest impact on the green growth capacity of state-level new districts, followed by corporate green capacity, park output benefits, NGO supervision and guidance, and public participation. From each region, Pudong New Area has the largest green growth capacity, followed by Binhai New District, Nansha New District and Jinpu New District. Among them, the development of the Pudong New Area is the most balanced and the scores of each sub-subject are at a relatively high level. The indicators with larger weights are all superior to the other new districts. The sub-divisions of Jinpu New District are relatively low; especially the government support ability scores that have the greatest impact on the new district's green growth capacity are far lower than those of other new districts, indicating that the government of Jinpu New District should increase its support.

Although this article has achieved some research results, there are still some deficiencies. First of all, this paper does not pay attention to the mechanism of the green growth capacity of the national-level new district. In the future research, this theme can be further studied from the perspective of formation mechanism. Secondly, in the research method, this paper does not consider the relevance among the various indicators, especially the sub-capabilities. Therefore, in the future research, the ANP model that considers the relationship between indicators can be included in the optimal combination evaluation model.

\section{References}

Ditlev-Simonsen, C. D., \& Wenstøp, F. (2013). How Stakeholders View Stakeholders as CSR Motivators. Social Responsibility Journal, 9, 137-147. https://doi.org/10.1108/17471111311307868

Freeman, R. E. (1984). Strategic Management: A Stakeholder Approach. Boston: Pitman.

Guo, Y. J. (2002). Comprehensive Evaluation Theory, Method and Application. Beijing: Science Press, 44-51.

Huang, Z. S., Hu, P., \& Nie, J. J. (2012). Cross Efficiency Evaluation Method Based on Maximizing Deviations. Operations Research and Management Science, 21, 177-181.

Li, B. Z., Xu, G. Y., \& Su, Y. (2013). Regional Knowledge Acquisition Model Based on Optimal Combination Weight-The Empirical Analysis of 31 Provinces. China Soft Science, 12, 68-81. 
Li, L. Y. (2015). State Rescaling and National New Area Development in China: The Case of Chongqing Liangjiang. Habitat International, 50, 80-89. https://doi.org/10.1016/j.habitatint.2015.08.009

Li, M. J., Chen, G. H., \& Chen, Y. T. (2004). Study on Target Standardization Method of Comprehensive Evaluation. Chinese Journal of Management Science, 12, 45-48.

Li, X., Zhao, Y., Shi, C. et al. (2015). Application of Water Evaluation and Planning (WEAP) Model for Water Resources Management Strategy Estimation in Coastal Binhai New Area, China. Ocean \& Coastal Management, 106, 97-109. https://doi.org/10.1016/j.ocecoaman.2015.01.016

Peng, J., Wei, H., Li, G. C., Chen, X., \& Yuan, Y. (2015). Research on Location Accessibility of National New Areas Based on Urban Agglomerations. Geographical Research, 34, 3-14.

Wang, X. J., Guo, Y. J., \& Zhao, L. Q. (2005). The Method of Dynamic Constitution Evaluation and Its Application in Supplier Selection. Management Review, 17, 40-43.

Ye, H., Li, G. C., Li, L., Wang, Q., \& Zhang, H. (2015). Development Potential and Future Direction of National New Areas-A GRNN Approach. Economic Geography, 35, 92-99.

Zhao, D. F., Wu, C. Y., \& Shang, H. (2018). Study on Influencing Factors of Green Growth Capacity for National New Areas. Science \& Technology Progress and Policy, in Press. (In Chinese) 